\title{
Political Cartoons in Commercial Advertising in Early Twentieth Century China
}

\author{
Xiaoqing Ye \\ Department of International Studies, Macquarie University \\ Sydney, NSW 2109, Australia \\ Tel: 61-2-98507946 E-mail: xye@humn.mq.edu.au
}

\begin{abstract}
Though advertising has long existed in China, the extensive use of advertisements, especially visual images, to excite the consumers' imagination only started in the early twentieth century in the treaty ports, Shanghai in particular. Many of the commercial advertisements of the period have clear political connotations, such as the 1911 Republican Revolution. This article studies commercial advertisements in early twentieth century China in their political and social context, in particular how advertisements tried to capture consumers' aspirations for progress and prosperity.
\end{abstract}

Keywords: Commercial advertising, Political cartoons, Early twentieth century China

\section{Introduction}

Perhaps no one could object to the view that advertising is as old as history, but it has only been since the mid nineteenth century that advertising, in the sense of the visual representation of commodities, together with exhortations to buy that particular commodity, has become a preponderant factor in everyday life in the industrial world (Richards, 1991:1). The earliest extant illustrated advertisements in China can be traced back to the Song (Bai, 2003:1). (Note 1) In modern times, however, advertising in China began in the treaty ports, particularly Shanghai, with the arrival of the modern press in the second half of the nineteenth century. The extensive use of illustrations, including political cartoons, in commercial advertising, started to appear in newspapers during the first decade of the twentieth century. (Note 2) A combination of factors - the development of a commodity culture, the use of illustrations to convey information, the rise of the modern press and social and political conditions in China contributed to this new marketing strategy. The significance of advertisements as historical documents has been already noted by many scholars. An examination of the political aspects of advertisements gives us a vivid sense of social anxieties and the aspirations, real and manufactured, of the time.

\section{Consumption and patriotism}

Wide acceptance of patent medicine, or "restorative medicine", was a common phenomenon of the nineteenth century world. Patent medicine was aggressively advertised in the press during the period under discussion. In Japan, during the period 1894-1917, the highest percentage of advertisements was for patent medicines (47\%), followed by cosmetics (12.5\%) (Yamaki, 1992:96). In Victorian England, patent medicine advertisements made up 25\% of all advertisements (Loeb, 1994:105). This fad for patent medicines in the West is attributed to ignorance of modern science and a generally low average life expectancy. Such products promised a long and healthy life in circumstances when longevity and health were the exception rather than the norm. "The snake-oil salesman of the 19th century resembled his counterpart of the 17th century: both sold what was essentially an existential idea." (Berman, 1981:71,73, 75). (Note 3) The British medical establishment, and the government, tried to wipe out such patent medicines. From 1868 to 1909, Parliament passed six acts designed to eliminate this sort of quackery (Richards, 1991:170-171). (Note 4)

At about the same time, both imported and locally produced patent medicine also flourished in China. (Note 5) Chinese traditional medical theory held that the body needs constant "fortification" to maintain the proper balance and flow of $q i$ within the body, and thus avoid the development of disease. Tonics of any sort, from ginseng to magic mushrooms and countless natural remedies, are part of Chinese daily life. The theory of western patent medicine is based on the theory of humors of the ancient Greeks, which regarded the circulation of blood as the key to the maintenance of balance, and thus health, of the human body (Lears, 1994:142). This was very similar to the native Chinese theory about $q i$ and $x u e$ 
'blood'. Qi is yang and xue is yin, and the balance between them is essential for the well-being of the human body. Western patent medicines, then, could be understood and accepted in Chinese terms. One of the first western patent medicines to appear on the Chinese market was Dr. William's Pink Pills for Pale People (Zhang, 1994: 91; Guojia tushuguan fenguan wenxian kaifa zhongxin, 2001: Vol. 10, 234-235, 254-255, 274-275). Soon Chinese businessmen were producing their own patent medicines. In Shanghai, which was well-disposed to western material culture and western goods generally, local producers often falsely claimed a foreign origin for their goods. Advertisements for patent medicine combined the consumers' desire for longevity with their admiration for Western products. After the 1911 Revolution, however, the consumption of patent medicine was presented in quite a different way, in the context of a newly emerging Chinese nationalism.

During the 1911 Revolution, a tonic called Man Made Self Propagating Blood (人造自來血) was promoted as the key to democracy. Advertisements for this elixir stressed that Chinese, in order to cross "the sea of bitterness" of the long political battles ahead, needed a healthy body, which this particular product could guarantee. When it first appeared in the market in 1907, it was called Boluode Blood Fortifying Miraculous Medicine (博羅德補血聖藥), the brand name Boluode in the title (in Shanghai dialect pronounced bolúda) deriving from the English word 'blood'. It was manufactured by the Shanghai International Dispensary Co. Ltd. (上海五洲大藥房), which claimed they had obtained the prescription from a British royal doctor. It did not sell well. The company thought that the name was not catchy enough, and changed it to Man Made Self Propagating Blood. It quickly became a commercial success.

The owners of the Shanghai International Dispensary were Huang Chujiu 黃楚九 and Xia Cuifang 夏粹芳. Xia was the founder of the Commercial Press. In 1890, Huang established The Grand Eastern Dispensary Ltd (上海中法大藥房). He produced a tonic called Ailuo Brain Strengthening Liquid (艾羅補腦汁), the English name of which was Yale Stimulant Remedy. He claimed that he had obtained the remedy from an American doctor, Dr. T. C. Yale. (艾羅 ailuo is pronounced yélu in Shanghaiese). Shanghaiese had developed a taste for western products of all types, and the tonic sold very well. However, there was no Dr. Yale. The name Yale was derived from the English word "yellow", a translation of Huang, the owner's name. The initials T. C. are from his Chinese name, Chujiu.

The Ailuo Brain Strengthening Liquid asserted that having an intelligent brain was the key to success in making money: "Is the only purpose of continuous industrial and commercial competition between continents during the twentieth century only to gain wealth? Is not the aim of making money to gain happiness in life? To survive in this worldwide competition, you need a smart brain. If you lack outstanding intelligence, if you don't have a strong brain, you cannot achieve your goals in life. Happiness in the world depends on wealth. Wealth comes from a strong brain. Since this pharmacy has been selling Ailuo Brain Strengthening Liquid, its reputation has spread throughout the world. Even women and children realize its value. From now on, you too can use this medicine to gain wealth. It will not be long before the gap between the rich and poor will disappear. You gentlemen are all living in a time of fierce competition. How could you not purchase Ailuo Brain Strengthening Liquid immediately? It will strengthen your brain, make your dreams come true and enable you to enjoy happiness in life." (Shenbao, August 31, 1911). Huang made a fortune with this product. One day a foreigner turned up in Shanghai, and announced that he was Dr. Yale's son. His father had died, and he wanted claim his share of the profit. Huang paid the visitor a large amount of money to get rid of him (Zhang, 1994:74-75).

The number of advertisements for Man Made Self Propagating Blood was enormous. Before the 1911 Revolution, however, they did no more than stress the benefits of this elixir for general well being. Their logo was a Daoist immortal, and their advertising ran like this: "The products of the International Dispensary Company on Simalu in Shanghai, such as Man Made Self Propagating Blood and African Tree Bark Pills, work as fast as galloping horses. The sick will get rid of their maladies immediately and the healthy can look forward to a long life. Hygienic compatriots should propagate the message as a matter of importance" (Shenbao, February 4, 1909). Early advertisements for Man Made Self Propagating Blood stressed that "compatriots with a sense of hygiene simply must have it". The advertisement was capitalizing on the then trendy concept of "hygiene". After the introduction of running water in Shanghai during $1880 \mathrm{~s}$, weisheng 'hygiene' emerged as a new concept far wider than just keeping clean. It came with a whole package of desirable qualities: being hygienic meant being progressive, open minded and fashionable. If someone was accused of being 'unhygienic', it did not only mean that he didn't wash, but also that he was uneducated and backward (Ye, 2003:52).

On the 9th of September 1911, the Shenbao carried testimonials from several educated consumers as to how effective the product was (Shenbao, September 9, 1911). Even on 11 October, the main theme of the advertisement was that Man Made Self Propagating Blood was "the best medicine to cure twentieth century anemia" (Shenbao, October 11, 1911). However, on the 23rd of October, a new advertisement for Man Made Self Propagating Blood reacted to the new wave of refugees who fled to Shanghai from the political turbulence in Hubei with a certain degree of political ambiguity: "To all gentlemen who have come to Shanghai and Zhejiang to escape chaos. Recently chaos has erupted in Hubei and Sichuan, and the number of gentry and merchants from those places who have brought their families to Shanghai has 
reached two hundred thousand. Such an arduous journey is both exhausting and worrying. Furthermore, being away from home, you may be unaccustomed to the climate and customs of an unfamiliar place. Now that you have arrived, you had better pay attention to hygiene. Man Made Self Propagating Blood of this dispensary is the best way to restore blood and $q i$, and help you recover your energy. Many Shanghai gentry and merchants have relatives who have fled to Shanghai. Usual hospitality, such as giving presents or inviting people to a theatre or a western restaurant is a waste of money and of no practical use. Why not purchase Man Made Self Propagating Blood as a present?" (Shenbao, October $23,1911)$.

This advertisement responded to temporary migration during the Revolution without any political comment. However, on the 1st of November 1911, twenty days after the Revolution broke out, the theme of the advertisement changed. It now claimed Man Made Self Propagating Blood could aid the "transition from autocracy to the Republic". The cartoon shows a boat with men and women on the sea, with 人造自來血, the Chinese name of the tonic, emblazoned on the sail. The caption reads: "Attention, all patriotic men! Heroes can create the trend of the time; the times can also create heroes. The current situation changes day by day, the affairs of the country are in a state of emergency. This is exactly the time when heroes can utilize their talents and real men can fulfill their dreams. However, to achieve extraordinary feats, you must have a perfect body. To participate in the enterprise of blood and iron, (Note 6) you need Man Made Self Propagating Blood from our pharmacy. Once you take our product, your body will be strengthened and your intelligence will be increased. Our pharmacy is producing Man Made Self Propagating Blood to meet the demands of soldiers and citizens involved in the enterprise of blood and iron. Is this not a rewarding thing to do? Our fellow citizens are great heroes, magnificent men. For those who yearn to hear, for those who yearn to try, the following illustration will show you how to use it" (Shenbao, November 1, 1911). The same theme was used for promoting the product repeatedly. In December readers were urged: “This is the time of blood and iron competition (鐵血競爭時代). If ordinary patriotic men want to increase their fighting ability, they had better take our blood elixir. This will not only strengthen their blood, but their spirit as well. It can also cure anemia. Compatriots! Please pay attention!" (Shenbao, December 3, 1911) Another headline a few days later called the blood elixir "the source of strengthening our country and our race." (Shenbao, December 22, 1911). As well as claiming a role in the developing political situation, this medicine continued to be marketed for more practical ends. "The uprising in Hubei province has been supported by the whole country. However, there is no lack of people fleeing to Shanghai to escape the turmoil. The hardships involved in this travelling can hardly be expressed. People from Hubei, Jiangsu and Zhejiang provinces have not been able to avoid witnessing gunfire, and are shocked and frightened. As a result of being exposed to the cold wind and rain during their flight, people can fall ill. If you do not search for a cure and delay for too long, your illness will become incurable. You must immediately recuperate and regulate your body ... With benevolent intentions, this proprietor wants to bring happiness to our twentieth century compatriots. So please buy this product immediately." (Shenbao, November 19, 1911).

At much the same time, another dispensary, the Shanghai Luowei Pharmacy Company (上海羅威藥房) also owned by Huang Chujiu, was promoting products called Blood Essence (血素), Brain Essence (腦素) and Kidney Essence (腎素). It claimed that these were the latest products to strengthen the body and strengthen the race. "Dear compatriots: the army uprising in Wuhan affects the Han compatriots of the whole country ... All those who care for their compatriots, those who espouse righteousness and virtue, should try to support them and join with them to show their love for their compatriots... This pharmacy has great ambition but its strength is meager. We have exhausted ourselves to the limit in assisting our Chinese compatriots. So please purchase this product and send it to Hankou. If you do this, the situation will be greatly improved, and your compatriots will be very grateful. If our heroes obtain this tonic, the task of the Han race will be greatly aided. This is the current task of the Han people, and the support of all compatriots is important. This righteous uprising will succeed, and the task of the Han race will be quickly accomplished." (Shenbao, November $5,1911)$.

Huang Chujiu, one of the founders of the company, was nicknamed “German brain” (強門頭腦) (in Shanghaiese 強門 chengmen sounds like 'German') - an indication of the esteem in which German technology and business acumen was held. The other owner was Xia Cuifang, the founder of the Commercial Press. So it is not surprising the product was so cleverly marketed. Both the Man Made Self Propagating Blood and Yale's Brain Strengthening Liquid were sold not only in Shanghai, but also throughout China and even South East Asia. (Zhang, 1994:74-75)

Another product of the Grand Eastern Dispensary Ltd was the Sunshine Iron Pills (日光鐵丸), formulated by Dr. Wong. The advertisement shows a man in a tuxedo standing on a bottle of Sunshine Iron Pills giving a speech. The text reads: "The situation in China deteriorates daily... Everybody must be prepared to carry heavy burdens. Being responsible for the country means that everyone must have a strong body and be full of energy ... to achieve this aim, you had better take Sunshine Iron Pills". (Rao and Yang, 2004:342, 344).

Yet another product, the Clear Minded Wake Up Pill (清醒丸), claimed to cure heat exhaustion, vomiting, diarrhea, indigestion and drunkenness. It was a Chinese product, so "clear-minded" Chinese (or those who wished to be) should 
buy it. The illustration was a dragon spurting out a pill and words appearing in the clouds: "Block the leaking hole" and "Retrieve economic rights" (Shenbao, September 13, 1911).

A medicine particularly for the female reproduction system and general well-being was Fortify the Foundation Womb Pills (固本子宮丸): “Women make up more than half the population in the county and half of the family. The strength or weakness of the country, the prosperity or decline of a family, largely depends on women. So parents, husbands and brothers - it is your responsibility to make sure that your daughters, wives and sisters are healthy and strong." (Shenbao, September 7, 1911). At that time, social activists promoting women's education also stressed that women as mothers and wives were of vital importance to the country. The advertisement was designed to appeal to this strain of social thought as well as to women with gynecological problems.

\section{In the name of social progress}

Advertisements provide the price and maker of a product, but the key is in convincing people why they must have them. How could advertisements persuade people to purchase non-essential products, or products were not able to connected with patriotism, such as foreign goods?

The image promoted that it was to be modern, progressive and fashionable to have such goods, thereby distinguishing users from certain groups lower down the social ladder. As in the late nineteenth century West, "the attainment of the social ideal was determined not only by the cultivation of culturally desirable habits, attitudes or virtues, but by the acquisition of material things as well." (Loeb, 1994:10). An advertisement for Scot's Cod Liver Oil depicts two Chinese children climbing onto a table trying to reach bottles of oil. The headline says: "If you do not use this oil as a tonic to strengthen their bodies, they are truly unfortunate children." (Shenbao, October 2,1911). The clear message is that if you don't purchase this product for your children, you will fail to be responsible and caring parents. This language is no less threatening than some advertisements for patent medicine in the West about the same time: "Do Not Let Your Baby Die" or "Baby on the Battlefield". (Loeb, 1994:7).

New inventions, such as the sewing machine, or the sock machine, liberated women from time-consuming needlework. But what could women do with their newly found leisure time? In 1880s America, a sewing machine was presented as something which could offer new cultural and material standards. Women could make more beautiful clothes for themselves and their children, and have the time to cultivate artistic interests, such as painting. (Laird, 1998: plate 7) In China, prior to the 1920s, women were not encouraged to pursue artistic activities. (Note 7) As matter of fact, during the late nineteenth century, women in Shanghai were already gaining more time for themselves by buying ready made shoes and similar goods. In their leisure time they started to enjoy the theaters and the teahouses, traditionally the preserve of men. The male literati were not impressed (Ye, 2003:153-154).

The sock machine was first advertised in the Shenbao in 1911, just before the Revolution. It was a simple illustration of the machine. The caption says that it was made in Britain, and was much superior to similar products. "If important gentry and merchant families would like to purchase it, the price can be greatly reduced. If girls and ladies of famous families would like to purchase it, we can provide female instructors to teach you how to use it." (Shenbao, October 3, 1911). In a Shibao supplement of 1912, the headline of the advertisement for the machine becomes: "Do you want to make three dollars a day?" The illustration shows a Chinese woman, wearing quite plain clothes, standing by the machine. However, later advertisements were headed sensationally "China has woken up!" The woman in the new version is more modern looking, more glamorous than the earlier one. The woman in the second advertisement is sitting, not standing, with a small teapot and cup next to her, giving the impression that operating the machine is almost a leisure activity. The implication is that smart, attractive and fashionable women would choose to purchase this particular brand of sock machine (Guojia tushuguan fenguan wenxian kaifa zhongxin, 2001: Vol. 10, 203, 269).

However, this advertisement does not go further than suggesting the advantages in making some extra money, and it would be unrealistic to interpret this as a suggestion that women should assume the financial responsibility of supporting a family. The female version of the Sunshine Iron Pills, the Moonlight Iron Pills, does not claim anything other than being good for women's health. No social responsibility, no crisis in China, only that it was the product of the latest medical research (Rao and Yang, 2004:341). Social expectations for women are still clearly mainly domestic ones. A cartoon by Kitazawa Ratuken in Tōkyō Pakku (Tokyo Puck) in 1911 illustrated women's rights and duties in Japan in a similar way. "He contrasts the women who have awakened to women's rights with the women who have awakened to women's duties. The woman who has awakened to women's rights holds a book in her hand while the woman who has awakened to her duties is engaged in needlework." (Wilson, 2002:173). In China, a Japanese patent medicine for women, chüjōto (中將湯) used an illustration of a woman taking a straight and narrow path paved with chüjotot. At the end of the road, there is a stone tablet engraved with the word "health". The text says: "If you are sick, don't get lost and confused. There is only one way. For any sick women who want a smooth journey to recovery, without impediment, there is only one way: chüjōto." (Shenbao, November 5, 1911). On the packaging box, it claims it is "The only remedy for female complaints ever prepared in the whole world." It stressed it was prepared by Tsumura Juntendo Ltd, Tokyo, Japan (Zhang, 1994:32, 95). A common advertisement for chüjōtō was addressed to men: 
"Husbands or husbands to be must study women's health. If your wife gets uterine disease, or your mother succumbs to depression (憂鬱症), (Note 8) or your sisters have problems with menstruation, or any women in your extended family have any health problems, you must not delay. Read my article and become familiar with it, and at the same time take immediate action. Do not hesitate! Alas, time is like a thief." There was also a free booklet on women's health attached to this product. (Shenbao, September 1, 15, 25, 1911). From this advertisement, it would seem that the health of women had become a responsibility of men.

Successful commercial advertisements serve as a sensitive thermometer of social conditions and trends. A little over one month after the 1911 Revolution, two western style tailor shops in the International Settlement in Shanghai advertised themselves as playing an important role in marking the restoration of China to the Han Chinese by providing western clothing. One even claimed that wearing western style clothing would lead to the Grand Unity of the world. "Now we have restored the Great Han, all of our soldiers, merchants and students aim for datong shijie, the Grand Unity of the world. Cutting off our queues and changing our clothing is becoming more and more common. This is the reason the owner of this shop has invited highly skilled tailors to make western style clothing..." (Shenbao, November 27, 1911, December 2, 1911).

In 1911, before the Revolution, the gramophone was advertised as a music machine (唱戲機器). After the Revolution advertisements for the gramophone showed a group of several men sitting in a room, listening intently to a gramophone. The caption says: “The progress of the world (世界進步). Being instructed by the gramophone". (Shenbao, September 1, 1911; Guojia tushuguan fenguan wenxian kaifa zhongxin, 2001:16, 180-181).

Some time later, an advertisement entitled "match making" was not for a matchmaking agency at all, but for eyeglasses. The advertisement is a dialogue between a Mr. Zhong and a Miss Cheng, who date for the first time. "At the first meeting, Mr. Zhong could not find anything to talk about. He saw Miss Cheng's glasses were very nice, and asked where she had obtained them. She answered very seriously that she got them from a department store inside the YMCA on Dongmalu. They corrected her sight very effectively, and were not expensive. If Mr. Zhong was keen on looking after his eyesight, he should try them. Mr. Zhong answered in English: "Yes, I like it." (Rao and Yang, 2004:343). An educated, smart and desirable young man should certainly know how to look after his eyesight.

The most successfully marketed products accurately reflected the social mood and trends at the time. Failing to convince people meant failure in the marketplace. An example was the promotion of a brand of Italian olive oil. The illustration shows a Chinese in convict garb, who had been reduced to this state because he could not resist the temptation of stealing some olive oil. This image did not appeal to the Chinese consumer. (Xu, 2006:132). (Note 9) Despite the popularity of Western food in the large cities, olive oil was never accepted by the Chinese. There may be many reasons for this, but such advertisements certainly did not help. (Note 10) There were derogatory images of Chinese used in commercials in other parts of the world. In the United States of the late nineteenth century, an advertisement for rat poison showed a Chinaman holding a rat, his pigtail looking much like the rat's tail, and the caption saying "They must go!" (Bai, 2003:62). However, that was a different time and place.

\section{Capitalizing on the national crisis}

It is by no means unusual to use current political issues to stir up public emotions in the interests of promoting various products. In Victorian England, advertising agents presented themselves as empire builders. Current affairs, especially British military victories, were good advertising material. During the Opium War of 1840, when Zhenjiang, the last fortified city on the Yangtze fell, a grocer and tea shop in High Street, Oxford printed the news with an illustration of the battle on their shopping bag:

"The City of Chin-Kiang-Foo is more than four miles in circumference. The parapet being so thick and strong that cannon balls had scarcely any effect on it. The garrison, at the time of the attack, consisted of 3,000 men, of whom 1000, and 40 Mandarins of rank were killed. The first man who mounted the top of the wall was Lieutenant Cuddy, of the Grenadier Company of the 55th. He behaved with matchless gallantry - slowly, but firmly, he climbed the ladder: on reaching the top he waved his sword, and then assisted his men over; but receiving a wound, which disabled him for the rest of the day, he sat down, bound it up, and continued cheering on his men until the close of the attack. The Tartars fought with great bravery - made repeated charges on our men with their long spears, and disputed every inch of ground. The loss of the British, killed and wounded, was - Navy 94, Army 145, total 169."

A further connection between British military victories and its beneficial effects on British commerce can be seen from the following: "In November 1858 news came through that British troops had triumphed once again over the antiquated armaments of the Imperial Chinese Army - they were even able to burn the imperial summer palace at Pekin before the Treaty of Tien Tsin guaranteed British opium traders free access to a number of ports. But the opium trade was not the only one to benefit. Strachan and C., Dealers in Fine Tea of 28 Cornhill opposite the Royal Exchange, took space in the advertisement pages of the Family Friend to make an announcement to tea drinkers. This said that the war with China 
was over, that open communication with China was now a "fact beyond recall" and as a result tea prices must inevitably fall". (Hindley, 1972:117, 118).

There is some similarity between such advertising and later advertising in China, both appealed to a sense of national anxiety among potential consumers. Certain aspects of anxiety in Victorian England - the decline of the empire, loss of prestige, in a way is similar to the sense of crisis in China. However, the intensity of sense of crisis in China was far greater than social anxiety in England. It is not difficult to imagine that it must have emphasized how important personal strength must have been to the citizens of the "sick man of Asia". So we see the emergence of marketing techniques in linking certain products to patriotism and the demands of the new age.

The first political press in China was a result of the war China lost to Japan, and the development of the modern Chinese political press had close links to Japan (Judge, 1996:20-31). Although manga had a long tradition of making fun at society and the hierarchy, there was one thing absolutely off limits. "While it was legitimate to mock the government and its leaders, it was not legitimate to make fun of the national patriarch, who embodied the nation-state in his person." This was not the case in China. The extensiveness of criticism and satire towards all social groups at all levels was such that no social group or individual was immune from being ridiculed or attacked, including the imperial court itself. The sense of satisfaction Japan had for its progress was in sharp contrast to the social mood in China. A few examples show the difference. In 1879, a Japanese cartoon showed two men in a race. The comment on the Chinese was: "With that big body he cannot walk at all, so everyone makes fun of him. Hey, look! He's walking Chinese-style higgledy-piggledy." The caption referring to the Japanese read: "He's little, but he is travelling as light as a dragonfly. He sure is fast-footed, isn't he?" By the turn of the century, after the Japanese government had successfully renegotiated the "unequal treaties", the difference in mood was even more marked. An 1899 cartoon by Kitazawa Rakuten showed a stylishly dressed Japan throwing a reception for the family of civilized nations, to which it now belonged (Duus, 2001:986, 981, 984).

Patriotism was not the exclusive capital of Chinese companies. Some foreign businesses also tried to cash in on the trend. Soon after the 1911 Revolution, a Western company which sold, amongst other things, hair-cutting scissors, advertised their usefulness in removing pigtails for the citizens of the new Republic (Shenbao, December 3, 1911). A Japanese medicine, Jintan (仁丹) had been previously advertised as having some sort of magical effect. About one month after the Revolution, it changed its tune. Keeping the original logo, the text now read: "The prosperity of a country, the fortune of a family, all rely on the abundance $q i$ and blood of its citizens. Abundant qi and blood comes from having a strong body. A strong body comes from taking Jintan. If all of you desire the prosperity of the country and the fortune of the family, you can only protect your health by taking Jintan every day." (Shenbao, November 30, 1911). The next advertisement reverted to stressing its magical effect, but the illustration shows masses of people of all groups of society who have benefited from regular doses of Jintan (Shenbao, December 22, 1911).

When Mao Zedong was interviewed by Edgar Snow in Yan'an, he told him that when he was a young man, after the 1911 Revolution, he was passionately patriotic, searching for a way to save China. "I began to read advertisements in the papers. Many schools were then being opened and used this medium to attract new students. I had no special standard for judging schools; I did not know exactly what I wanted to do. An advertisement for a police school caught my eye and I registered for entrance to it. Before I was examined, however I read an advertisement of a soap-making "school". No tuition was required, board was furnished and a small salary was promised. It was an attractive and inspiring advertisement. It told of the great social benefits of soap making, how it would enrich the country and enrich the people. I changed my mind about the police school and decided to become a soap maker. I paid my dollar registration fee here also." (Snow, 1937:167). (Note 11) I have not been able to find that particular advertisement, but the link between hygiene and personal strength, and between personal well being and national survival, clearly made an impression on the young Mao. Taking of patent medicines and being 'hygienic' was more than a matter of personal well-being, it was a matter of national survival. Not long after the Revolution, advertisers used the new National Flag as a background to their products (Guojia tushuguan fenguan wenxian kaifa zhongxin, 2001: Vol.11, 411). The early attempts of advertisers to link consumption of their products with patriotic duty did indeed have a role to play in modern Chinese history.

\section{References}

Bai, Guang. (2003). Zhongwai zaoqi guanggao zhencang yu pingxi [A critical analysis of collections of early advertisements from China and the world]. Beijing: Zhongguo guangbo dianshi chubanshe.

Berman, Ronald. (1981). Advertising and social change. London: Sage Publications.

Bi, Keguan. (2005). Zhongguo manhua shihua [History of Chinese cartoons]. Tianjin: Baihua wenyi chubanshe.

Duus, Peter. (2001). Presidential Address: "Weapons of the weak, weapons of the strong - The development of the Japanese cartoon". Journal of Asian Studies, Vol. 60, No. 4 (November) 965-97. 
Geremie R. Barmé. (2002). An artistic exile - A life of Feng Zikai (1898-1975). Berkeley: University of California Press.

Guojia tushuguan fenguan wenxian kaifa zhongxin ed. (2001). Qingdai baokan tuhua jicheng [Collected newspaper illustrations of the Qing dynasty]. Vol 10. Beijing: Quanguo tushuguan wenxian suowei fuzhi zhongxin.

Hindley, Diana and Geoffrey. (1972). Advertising in Victorian England, 1837-1901. London: Wayland Ltd.

Judge, Joan. (1996). Print and politics - Shibao and the culture of reform in late Qing China. Stanford: California: Stanford University Press.

Laird, Pamela Walker. (1998). Advertising progress - American business and the rise of consumer marketing. Baltimore and London: The Johns Hopkins University Press.

Lears, Jackson. (1994). Fables of abundance - A cultural history of advertising in America. New York: Basic Books.

Loeb, Lori Anne. (1994). Consuming angels - advertising and Victorian women. New York and Oxford: Oxford University Press.

Rao, Huaimin and Yang Xinsheng eds. (2004). Zhongguo jindai manhua shiji xunzong [A search for traces of the history of the modern cartoon in China]. Changsha: Yuelu shushe.

Richards, Thomas. (1991). The commodity culture of Victorian England - advertising and spectacle, 1851-1914. London and New York: Verso. First published by Stanford University Press, 1990.

Snow, Edgar. (1937). Red star over China. Victor Gollancz Ltd, 1937. Reprinted Pelican Books 1972.

Wilson, Sandra. (2002). Nation and nationalism in Japan. London and New York: Routledge, Curzon.

$\mathrm{Xu}$, Junji. (2006) Zhongguo guanggao shi [A history of Chinese advertising]. Beijing: Zhongguo chuanmei chubanshe.

Yamaki, Toshio. (1992). Nihon kōkoku-shi. [A history of Japanese advertising]. Tokyo: Nihon keizai shimbun-sha.

Zhang, Yanfeng. (1994). Lao yuefenpai guanggao hua [Illustrated advertisements from old monthly calendars]. Taipei: Yingwen hansheng youxian gongsi.

\section{Notes}

Note 1. The earliest extant Chinese advertisement is held in the National Museum of China, Beijing. It is a Northern Song dynasty advertisement for a needle shop in Shandong. The illustration is a rabbit, indicating that the needles are as thin as rabbit's fur. (Bai, 2003:1)

Note 2. There was no unified term for such illustrations: youmohua, fengcihua or huajihua were commonly used. The word manhua, derived from Japanese manga, was first used in its modern meaning in Chinese by Feng Zikai in the 1920 s, and has now become the standard term. The first artist to use cartoons in advertising was Feng's mentor, Li Shutong. Both Feng and Li had studied fine arts in Japan. (Bi, 2005:20; Barmé, 2002:47-71, 92-97).

Note 3. Life expectancy in the United States at that time was about 47 for whites and about 33 for blacks. (Berman, 1981: 71,73, 75)

Note 4. The Sale of Food and Drugs Acts of 1875 and 1899, the Merchandise Marks Act of 1887, the Indecent Advertisements Acts of 1889, and the Poisons and Pharmacy Act of 1908 (Richards, 1991:170-171).

Note 5. Even now "restorative medicine" is not subject to regulation. The modern equivalents are the baojian yaopin "health preservation medicinal products". They are pervasive on television and prominent in street advertising.

Note 6. The allusion is to "Blood and Iron", the slogan of Otto von Bismarck, the Iron Chancellor of Germany. The term was adopted in China about the time of the 1911 Revolution to symbolize the qualities necessary for the survival of China.

Note 7. Political cartoons during the second decade of the nineteenth century often made fun of female students in new style clothing, or exhibiting other types of daring social behavior. (Rao and Yang, 2004: wanxiang juan, 281).

Note 8 . In this advertisement, the term youyuzheng is used. youyu traditionally had the meaning 'sad, depressed', but youyuzheng is a modern medical term for clinical depression.

Note 9. Xu does not provide the illustration or give details of the reference.

Note 10. A very successful example of this is Worcestershire Sauce, known in Chinese as lajiangyou "hot soybean sauce". It is still very popular in Shanghai. Few Chinese, if any, realize its foreign origins. At the time, it was advertised as Lea and Perrins Sauce, and the text notes that it came from Worcestershire, England. For an early advertisement, see Shenbao, September 1,1911.

Note 11. For information on 19th century soap advertisements in the United States and England, see Laird (1998: 300); Loeb (1994:11, 109, 112,115).

Note 12. Rao Haimin and Yang Xinsheng ed. Zhongguo jindai manhua shiji xunzong, Shehui wanxiang, Changsha: Yuelu shushe, 2004, p. 342, 344. 
Caption 1.

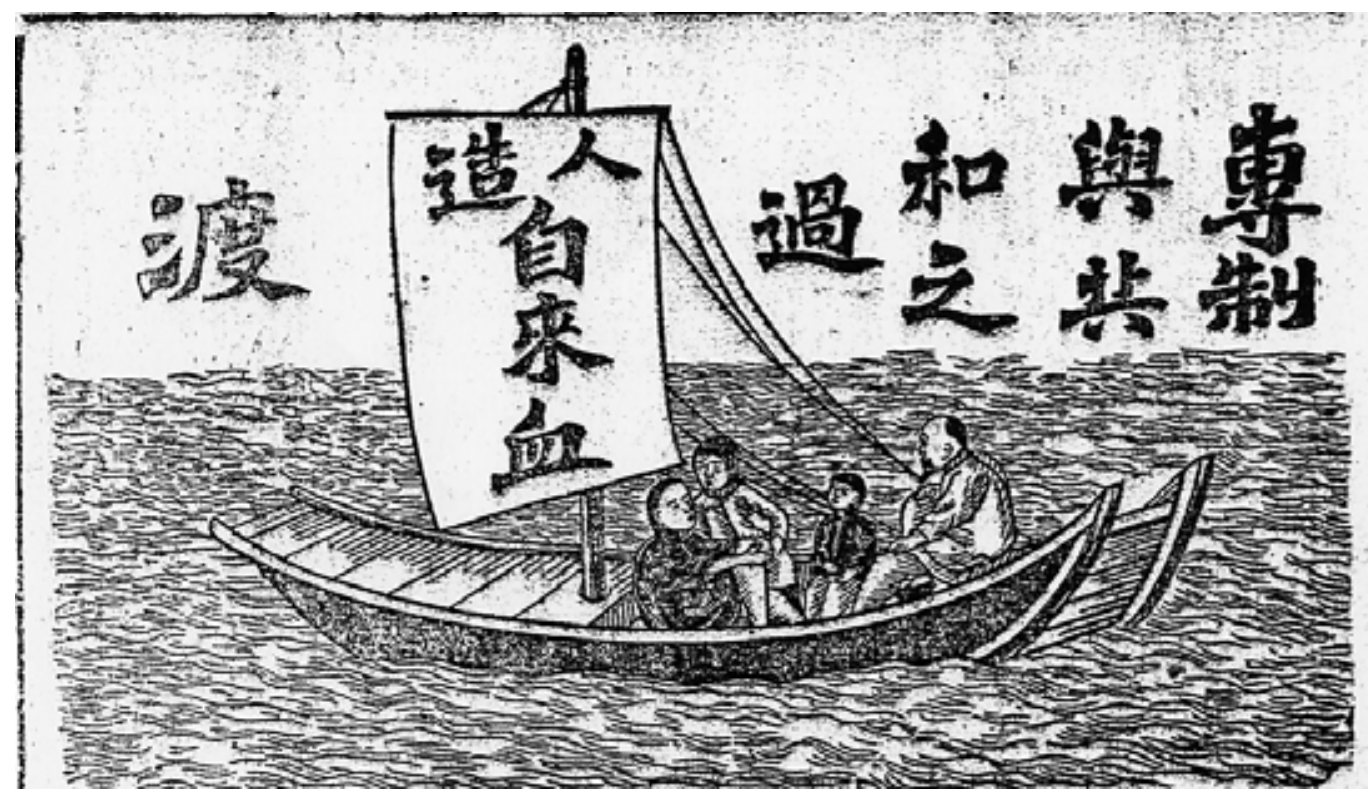

Note: Twenty days after the 1911 Revolution broke out, the theme of the advertisement changed. It now claimed Man Made Self Propagating Blood could aid the "transition from autocracy to the Republic". The boat is a symbol of crossing the vast "bitter sea".

Caption 2.

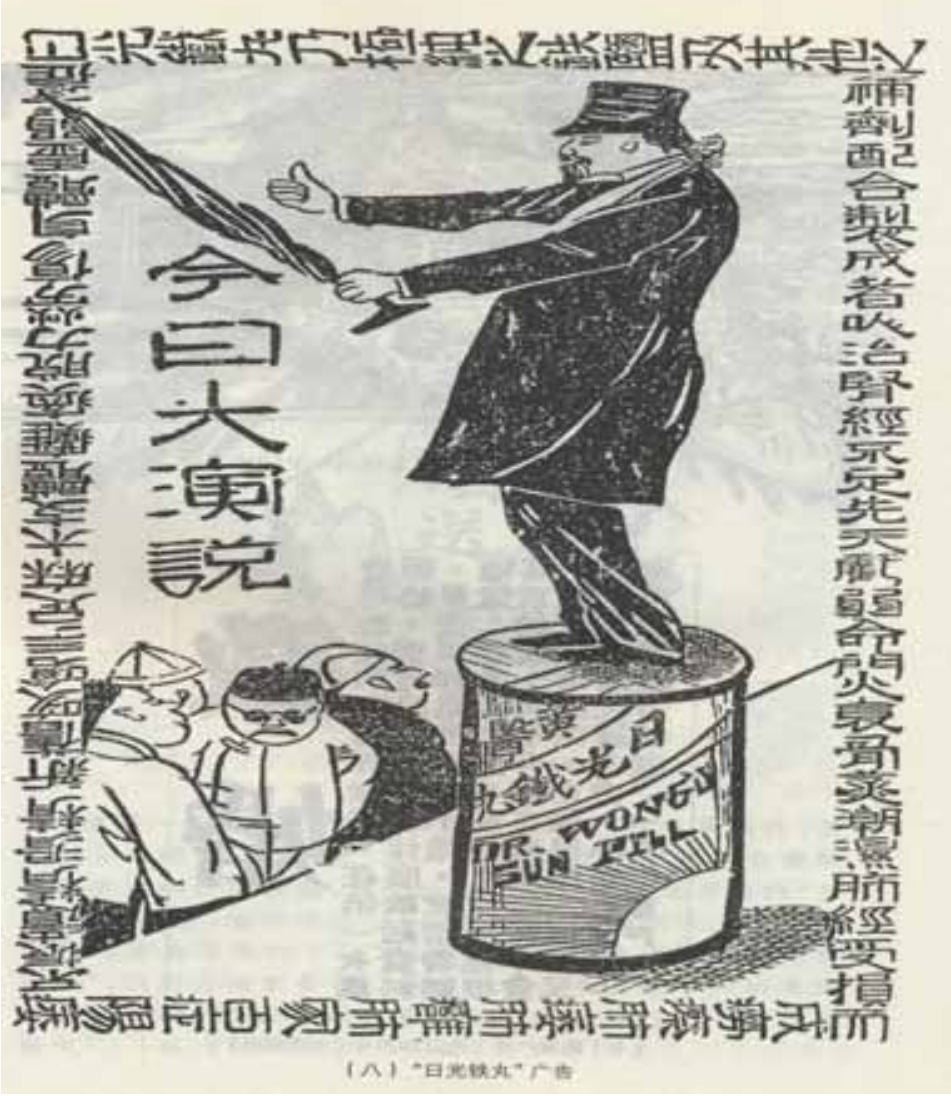

Note: The advertisement shows a man in a tuxedo standing on a bottle of Sunshine Iron Pills, giving a speech. The text related to this illustration reads: "The situation in China deteriorates daily... Everybody must be prepared to carry heavy burdens. Being responsible for the country means that everyone must have a strong body and be full of energy ... to achieve this aim, you had better take Sunshine Iron Pills". (Note 12) 


\section{Caption 3.}

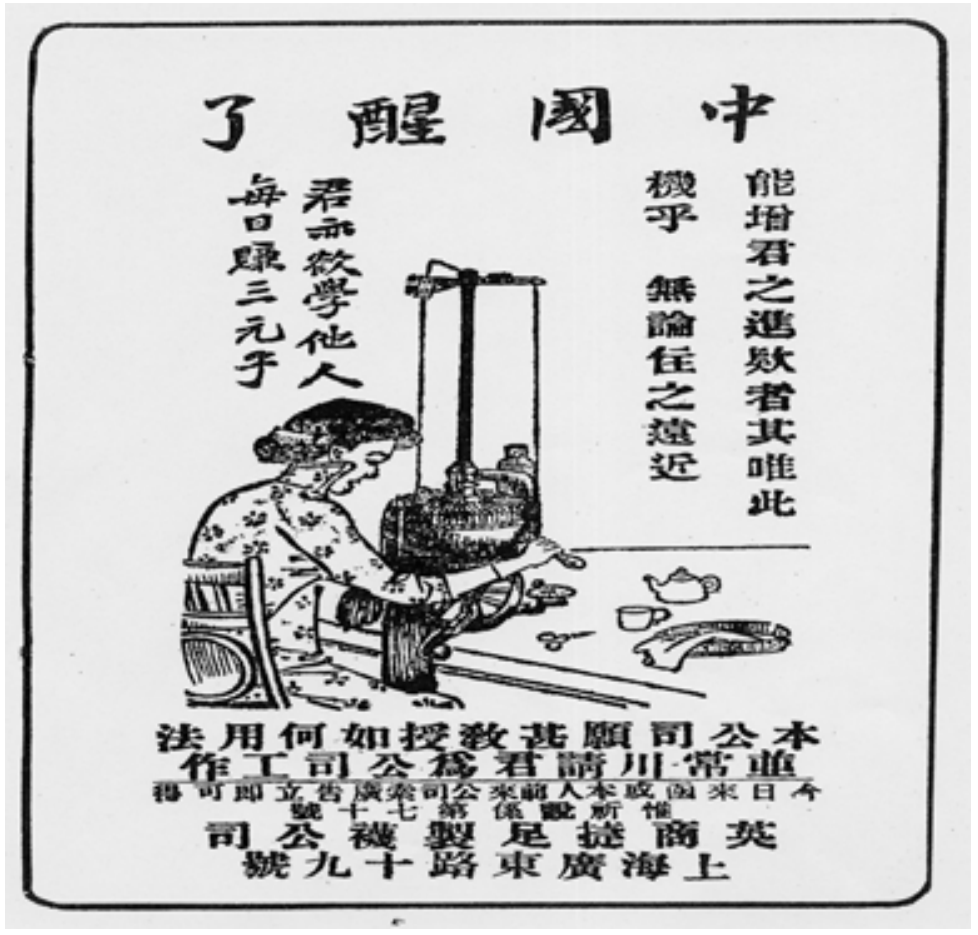

Note: This advertisement for a new sock-making machine has a sensational headline: "China has woken up!"

Caption 4.

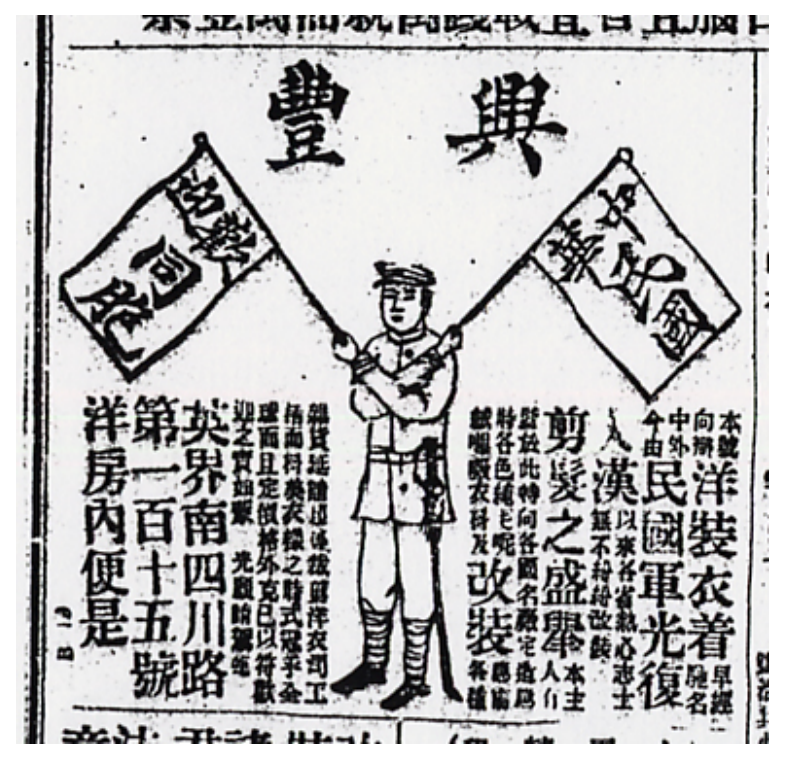

Note: Western style tailor shops in the International Settlement in Shanghai advertised themselves as playing an important role in marking the restoration of China to the Han Chinese by providing western clothing. 


\section{Caption 5.}

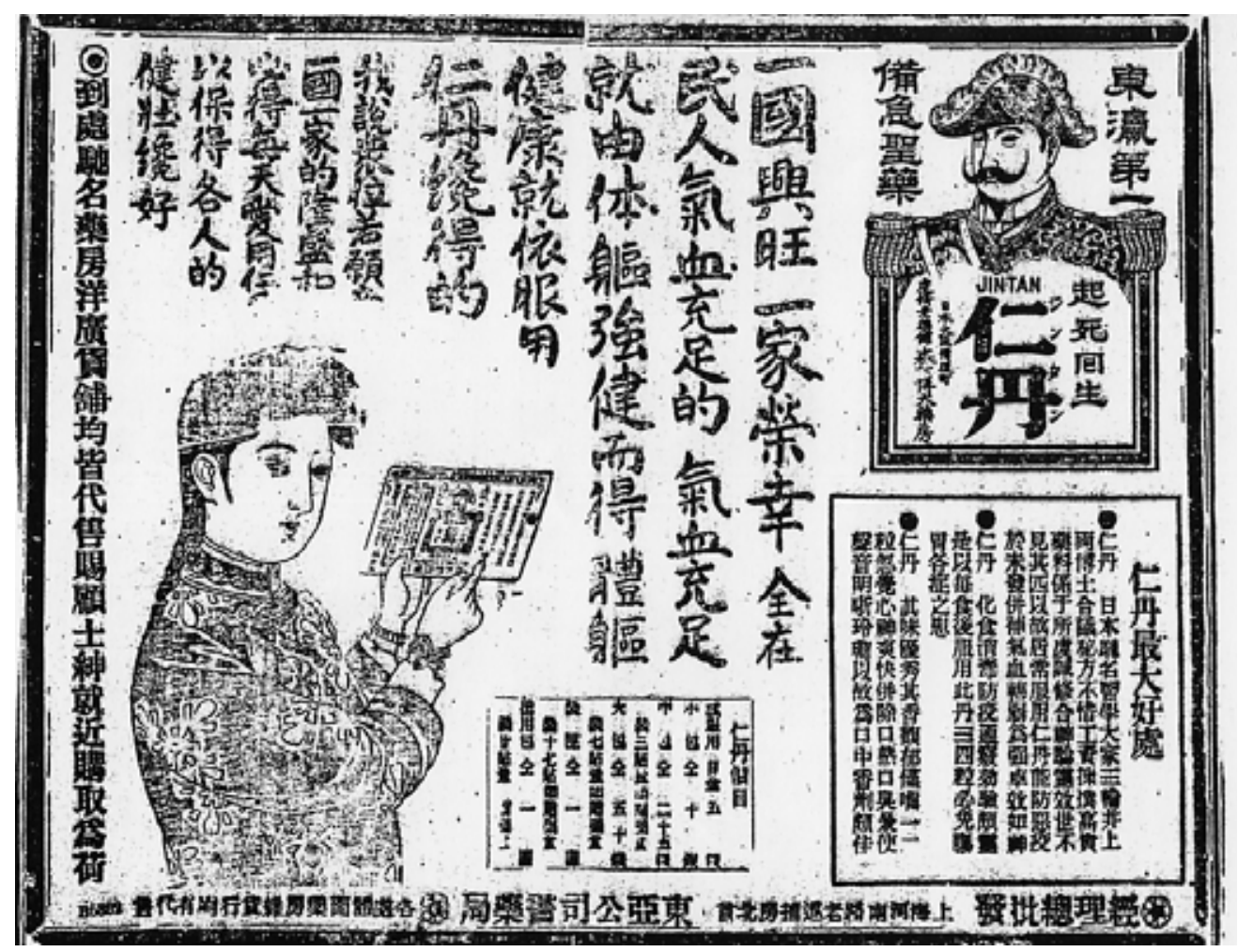

Note: The advertisement for a Japanese medicine, Jintan (仁丹), changed its theme immediately after 1911 Revolution, connecting "the prosperity of the country" with its product. 